\title{
Simulation of biomass gasification in circulating fluidized bed reactor by aspen plus
}

\author{
T. S. Pinho, A. M. Ribeiro, L. M. S. Silva \\ Departamento de Engenharia Química, CIETJ, Instituto Superior de Engenharia do Porto \\ (!SEP), Rua Dr. António Bernardino de Almeida, 431, 4200-072 Porto - Portugal \\ Tlf:+351228340500; email:Ims@isep.ipp.pt
}

1. Introduction - Biomass is the fourth largest source of energy in the world. Many consider it to be the best option, with the greatest potential as an alternative energy supply which meets energy requiremen ts, for ensuring future fuel supply. Biomass energy resources are potentially the world's largest and most sustainable energy source, a renewable resource comprising 220 billion oven-dry tons (about $4500 \mathrm{EJ}$ ) of annual primary production [1]. 1t is currently assumed that $5 \%$ of this energy could be mobilized to produce energy, i.e. a total of 225 EJ representing an energy equivalent ofmore than 5 billion tons ofoil equivalent, accounting for almost $50 \%$ ofthe world's total primary energy demand at present [2].

Hydrogen production is one of the most promising alternative energy technologies . The majority of experts consider that hydrogen has a significant role to play as an important energy carrier in the future energy sector [3]. Howe ver, it is a secondary form of energy that, like electricity, must be manufactured.

A promising way to generate hydrogen is by thermochemical conversion of biom ass to synthe sis gas, consisting of a mixture of $\mathrm{H}_{2}, \mathrm{CO}, \mathrm{CO}_{2}, \mathrm{CH} . \mathrm{i}, \mathrm{O}_{2}, \mathrm{~N}_{2}$ and tar. In order to maximize $\mathrm{H}_{2}$ yield, an $\odot$ steam circulating fluidized bed (CFB) gasification process was proposed. For this purpose a computer simulation model was developed using the commercial chemical processsimulator ASPEN Plus.

2. Model description - To model a CFB gasifier using ASPEN Plus, the overall process must be broken down into a number of subprocesses. This encompasses three stages: pyrolysis and pressure correction, modeled by two RYIELD blocks, volatiles combustion modeled by a RSTOIC block and the char oxidation and gasification reactions, modeled by a RPLUG block. In Figure I a flow diagram of the biomass gasification process is shown. Other blocks are used for helping these four blocks to simulate the above three processes. Two FORTRAN user-subroutines were created; one to correct the yield of the pyrolysis for a pressure of about $1.05 \mathrm{~atm}$ and the other to incorporate a kinetic model in the presence of diffusional limitations in the film around the particle and in ash voids. For the

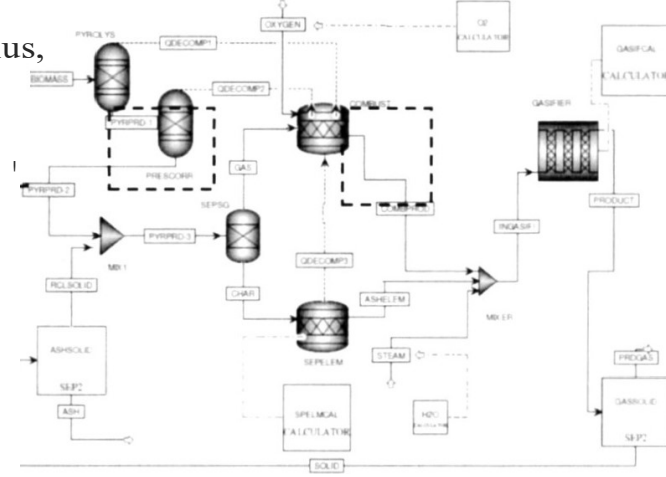

Figure 1 - ASPEN Plus process flowsheet for CFB biomass gasificat ion. present case the shrinking unreacted-core model was adopted. In addition the model is composed of four calculator blocks: one for solid residence time and gasifier height calculations (GASIFCAL), another that determine $\mathrm{s}$ the stoichiometric coefficients of $\mathrm{C}, \mathbf{H}_{2}, \mathrm{O}_{2}, \mathrm{~N}_{2}, \mathrm{~S}$, and ash from the proximate and ultimate analysis of the char (SPELMCAL) and finally 02 and H20 blocks that calculate the amounts of oxygen and steam to be used in the simulation based on fixed equivalence ratio (ER) and steam-to-biomass ratio (SBR) values.

3. Results and Discussion - Simulation results were compared with those in the literature [4] using steam with $\mathrm{SBR}=\mathrm{I}$. For three temperatures $\left(700,770\right.$ and $\left.820^{\circ} \mathrm{C}\right)$ significant differences in syngas composition were found. The cause for this inadequacy may be due to misused kinetic data. ln fact, data in [4] refer s to gasification catalyzed by olivine, while this work simulates non-catalytic gasification.

4. Conclusions - The kinetic model, together with the hydrodynamic equations used in this work, are a valuable too! in predicting the behavior of biomass gasification in a CFB gasifier. Nevertheless further validation is required with more suitable experimental data.

\section{References}

[I] S. O. Jekayin fa, V. Scholz, Energy Sources, Part A, 31, (2009) p. 687-697.

[2] S. Ladanai, J. Yinterback, "Global potential of sustainable biomass for energy, report O13", Uppsala: Departrnent of Energy and Technology, Swedish University of Agricultural Sciences; 2009.

[3] T. N. Yezirogl u, S. Sahin, Energy Convers. Manag e., 49, (2008) p. 1820-1831.

[4] S. Rapagnà, N. Jand, A. Kiennemann, P. U. Foscolo, Biomass Bioenergy, 19, (2000) p. 187-197 